two of them required induction for premature rupture of the membranes, and if these women are removed the statistical differences also disappear. Many obstetricians would not consider premature rupture of the membranes as a medical indication for induction as it does not pose such a threat to pregnancy as maternal hypertension or an abnormal antenatal trace of fetal heart rate. We realise, however, that others wish to see statistical significance as well as clinical significance, so we have reanalysed our data to include these seven women in the conservative group. This does not change the significance value given above as only one of the seven women had a caesarean section for fetal distress, detected as an abnormal cardiotocograph and a low scalp $\mathrm{pH}$ in the first stage of labour. The remaining women had spontaneous vaginal deliveries.

The supplementary analysis shows more clearly that routine induction of labour at 42 completed weeks of gestation significantly increased both the need for caesarean section for fetal distress $(6 \%$ v $2 \% ; 95 \%$ confidence interval $0 \%$ to $9 \%$ ) and the overall need for operative delivery for fetal distress ( $14 \%$ v $7 \%$; $95 \%$ confidence interval $0 \%$ to $14 \%$ ) with no effect on short term measures of neonatal outcome.

(Accepted 21 fuly 1988)

\section{Plasmacytosis and renal failure after readministration of streptokinase for threatened myocardial reinfarction}

\author{
N S Chan, Harvey White, Andrew Maslowski, \\ James Cleland
}

Green Lane Hospital,

Auckland, New Zealand

N S Chan, MRCP, cardiology registrar

Harvey White, FRACP, senior fellow, National Heart

Foundation of New Zealand James Cleland, FRACP, haematologist

Middlemore Hospital, Auckland, New Zealand Andrew Maslowski, FRACP, cardiologist

Correspondence to: Dr White.

Recent clinical trials have shown that early thrombolytic treatment with streptokinase reduces mortality and preserves left ventricular function after acute myocardial infarction. ${ }^{1.3}$ After successful reperfusion, however, the artery affected by the infarct may reocclude. Although streptokinase may be given again in an attempt to reopen the artery, there is a small risk of potentially serious allergic reactions. We describe such a rare event.

\section{Case report}

A 65 year old man was admitted to the coronary care unit with a half hour history of chest pain. Electrocardiography showed ST segment elevation in leads II, III, and AVF. Reperfusion was attempted with an infusion of 1.5 million units of streptokinase over 30 minutes. A heparin infusion was started at the same time and continued for 48 hours. Creatine kinase values were measured every two hours and an early peak rise of $1318 \mathrm{IU}$ was detected after 12 hours. The clinical course was uncomplicated until the fourth day, when he developed further chest pain associated with recurrent ST segment elevation in the inferior leads. He was given another dose of streptokinase ( 1.5 million units) over 30 minutes. Hydrocortisone was not given beforehand. Immediately after the streptokinase infusion he had rigors and became feverish. He had no rash or bronchospasm, and his blood pressure remained stable. Cardiac enzyme activities did not rise and recurrent myocardial infarction was prevented. Over the next few days, however, he developed a pronounced plasmacytosis and renal failure.

Initial investigations, including a full blood count, serum creatinine and urea measurements, and urine microscopy, gave normal results. On day 8 the total leucocyte count was $11 \cdot 5 \times 10^{4} / 1$, lymphocytes were $1.46 \times 10^{\%} / 1$, and a few "variant" lymphocytes were seen in the blood film. On day 9 an appreciable plasmacytosis was noted in the blood film, with a total leucocyte count of $17 \cdot 1 \times 10^{\%} / \mathrm{l}$, plasma cell count of $1 \cdot 20 \times 10^{9} / 1(7 \%)$, and plasma blasts count of $2 \cdot 22 \times 10^{9} / 1$ $(13 \%)$. Haemoglobin concentration was $156 \mathrm{~g} / \mathrm{l}$, platelets were $258 \times 10^{9} / 1$, and erythrocyte sedimentation rate was $46 \mathrm{~mm}$ in the first hour. Serum IgG concentration was $22 \cdot 8 \mathrm{~g} / \mathrm{l}$ with normal serum $\operatorname{IgA}$ and IgM values. Serum protein electrophoresis showed a diffuse increase in gammaglobulins without a monoclonal band. Serum C 3 was $1.67 \mathrm{~g} / 1$ and serum C4 $0.43 \mathrm{~g} / \mathrm{l}$. The urine protein value was ++ ; the sediment contained many leucocytes and fine granular casts, few hyaline casts, and no erythrocytes or erythrocyte casts. Electrophoresis of a concentrated urine sample showed a large amount of protein but no free light chains. The antistreptolysin $\mathrm{O}$ titre was 340 IU. Antinuclear antibodies were absent, and a direct Coombs test gave a negative result. His renal function, previously normal, deteriorated on day 8 with a serum urea value of $14.9 \mathrm{mmol} / \mathrm{l}$ and a serum creatinine value of $220 \mu \mathrm{mol} / \mathrm{l}$ (see figure). There was a subsequent progressive

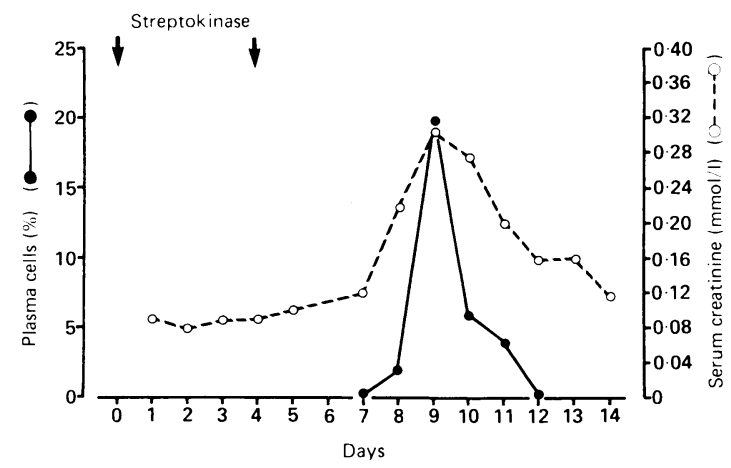

Relation between serum creatinine concentration, percentage of plasma cells, and time after administration of streptokinase

improvement in renal function, and the urea and creatinine concentrations had returned to normal by day 14. Plasma cells and plasma blasts had disappeared from the blood film by day 12 , when the total leucocyte count was normal.

The patient made a complete recovery and coronary artery surgery was performed for persisting severe angina.

\section{Comment}

Allergic reactions to streptokinase have been reported in $1 \cdot 7-18 \%$ of cases. ${ }^{4}$ The manufacturer's data sheet recommends that streptokinase should not be administered to patients who have received the drug five days to three months previously. We thought that it was safe for our patient to receive a second dose of streptokinase within four days of the initial treatment. To our knowledge there has been only one previous report of plasmacytosis after streptokinase treatment. ${ }^{5}$

The course of our patient's illness would suggest that the immune mechanism was an allergic or immune reaction to streptokinase with a dramatic rise in the number of plasma cells and plasma blasts after the second infusion of streptokinase. The high absolute plasmacytosis- $3.42 \times 10^{\%} / 1 \quad(20 \%)$, with a higher proportion of plasma blasts with a high nucleocytoplasmic ratio and nucleoli compared with plasma 
cells-suggested the possibility of more sinister haematological disorders, including plasma cell leukaemia and angioimmunoblastic lymphadenopathy. There was, however, no additional clinical or laboratory evidence for these diagnoses. The dramatic rise in the numbers of these cells was short lived with complete disappearance in three days. Although a renal biopsy was not performed, the renal failure was considered to be due to an acute hypersensitivity induced interstitial nephritis. Hydrocortisone, which was not given prophylactically to this patient, might have modified the immune and clinical response.

Management after thrombolytic treatment has been controversial and it is not clear whether coronary angioplasty is beneficial in preventing reocclusion of the reperfused artery. If threatened reocclusion occurs either within five days or after three months following initially successful thrombolysis our policy has been to reattempt reperfusion with streptokinase. In this patient reocclusion was prevented by readministration of streptokinase, but his severe symptoms of angina continued and coronary surgery was required. If thrombolytic treatment is to be repeated at a time when an allergic reaction is likely, non-antigenic agents such as recombinant tissue plasminogen activator should be used.

1 Gruppo Italiano Per Lo Studio Della Streptochinasi Nell' Infarcto Miocardico GISSI). Effectiveness of intravenous thrombolytic treatment in acute myocardial infarction. Lancet 1986;i:397-402.

2 ISIS Steering Committee. Intravenous streptokinase given within 0-4 hours of onset of myocardial infarction reduced mortality rate in ISIS 2. Lancet 1987; i:502.

3 White HD, Norris RM, Brown MA, et al. Effect of intravenous streptokinase on left ventricular function and early survival after acute myocardial infarction. $N$ Engl J Med 1987;317:850-5.

4 Sharma CVRK, Cella G, Parisi AF, Sasahara AA. Thrombolytic therapy N Engl f Med 1982;306:1268-76.

5 Straub PW, Boersma J, Rhyner N, et al. Plasmacytoma following thrombolytic treatment with streptokinase. Sch Med Wochenschr 1974;104:1891-2.

(Accepted 24 May 1988)

\section{Increased prevalence of bulimia nervosa among Asian schoolgirls}

\section{B Mumford, A M Whitehouse}

Transcultural Psychiatry Unit, Lynfield Mount Hospital, Bradford

D B Mumford, MRCPSYCH, senior registrar in psychiatry

University Department of Psychiatry, Addenbrooke' Hospital, Cambridge CB2 2QQ

A M Whitehouse, MRCPSYCH, clinical lecturer in psychiatry

Correspondence to: $\mathrm{Dr}$ Whitehouse.

Previous surveys of girls in school and higher education have yielded a prevalence of anorexia nervosa of 0.2 $0 \cdot 4 \%$ and of bulimia nervosa of $1 \cdot 3-1 \cdot 9 \%$. Few cases of anorexia nervosa or bulimia nervosa have been reported among non-white subjects. It might therefore be expected that the prevalence of eating disorders would be lower among Asian schoolgirls in Britain than among their white counterparts.

\section{Subjects, methods, and results}

We studied fourth and fifth year schoolgirls aged 14-16 at four schools in the Bradford metropolitan area selected for their high proportion of Asian pupils. The 26 item eating attitudes test and the body shape questionnaire were administered in the classroom by teachers. ${ }^{2}$ Subjects who scored above 20 on the eating attitudes test or above 140 on the body shape questionnaire were invited to attend for a semistructured interview at which the eating disorder examination was used. ${ }^{3}$ Details of their eating history were also collected. An eating disorder was diagnosed after discussion between us.

Overall attendance in the classes surveyed was $69 \%$ of the number enrolled; there was no reason to think that any of the girls were absent because of the survey. Girls of mixed or other ethnic origin or whose ethnic origin was in doubt were not included in the study population; 37 girls ( $6 \%$ of girls in school) refused to complete the questionnaire, and six questionnaires were inadequately completed and excluded. The remaining 204 Asian and 355 white girls constituted the survey population.

Scores obtained with the eating attitudes test had a skewed distribution and were logarithmically converted for statistical analysis. The mean score of the Asian girls was 10.6 (SD 9.0) and of the white girls 7.7 $(8 \cdot 0)$, the difference being significant $(t=4 \cdot 7$, $\mathrm{p}<0.001)$. The mean score obtained with the body shape questionnaire by the Asian girls was $73 \cdot 3(34 \cdot 2)$ and by the white girls $70.3(31 \cdot 6)$; this difference was not significant $(t=1 \cdot 1)$. Thirty $(15 \%)$ Asian and 42 $(12 \%)$ white girls had scores above the threshold for the questionnaires and were invited for interview; 22 Asian and 32 white girls were interviewed $(75 \%$ of the population invited). Bulimia nervosa was diagnosed according to criteria of the American Psychiatric Association ${ }^{4}$ in seven of the Asian and two of the white girls, giving a prevalence of $3.4 \%$ and $0.6 \%$ respectively, the difference being significant (Fisher's exact test, $\mathrm{p}<0.05)$. Anorexia nervosa was diagnosed ${ }^{4}$ in one Asian girl but was not found in any white girls.

\section{Comment}

The high prevalence of bulimia nervosa among the Asian girls in this survey was unexpected. Anorexia nervosa and bulimia nervosa are commonly thought to be the result of Western attitudes towards body shape, weight, and dieting behaviour. Data from the Indian subcontinent are scarce, but eating disorders are probably rare. This high prevalence of bulimia nervosa among Asian girls in the United Kingdom is probably a new phenomenon in these families. The Asian girls' higher scores with the eating attitudes test indicate that they were more concerned than the white girls about food intake and weight. Such concerns are likely to play a part in the aetiology of eating disorders.

A recent study in Birmingham showed an increased rate of self poisoning among young Asian women compared with British women. ${ }^{5}$ A previous study had found that the rates among Asians were lower than those among their white counterparts. This change suggests that Asians are increasingly adopting Western patterns of reacting to stress. Our finding of a higher prevalence of bulimia nervosa would seem to be a parallel phenomenon and highlights one difficulty facing Asian schoolgirls growing up in Britain.

We thank Mr W R Knight, director of educational services, Bradford, and the head teachers and staff at the schools for their cooperation in this study.

1 Garner DM, Olmsted MP, Bohr Y, Garfinkel PE. The eating attitudes test: psychometric features and clinical correlates. Psychol Med 1982;12:871-8. 2 Cooper PJ, Taylor MJ, Cooper Z, Fairburn CG. The development and validation of the body shape questionnaire. International fourmal of Eating Disorders 1987; 4:485-94.

3 Cooper Z, Fairburn CG. The eating disorder examination: a semistructured interview for the assessment of the specific psychopathology of eating disorders. International fournal of Eating Disorders 1987;6:1-8.

4 American Psychiatric Association. DSM III-R: diagnostic and statistical manual of mental disorders. Revised 3rd ed. Washington, DC: American Psychiatric Association, 1987

5 Merrill J, Owens J. Ethnic differences in self-poisoning: a comparison of Asian and white groups. Br f Psychiatry 1986;148:708-12.

(Accepted 2 fune 1988) 